\title{
Relato de caso de febre tifóide no Município de Maringá, Estado do Paraná
}

\author{
Report on typhoid fever case in Maringá, State of Paraná
Regiane Bertin de Lima Scodro ${ }^{1}$, Rubia Andreia Falleiros de Pádua ${ }^{2}$, Luciana Dias Ghiraldi², Sonia Maria de Souza Santos Farah ${ }^{3}$, José Ricardo Colleti Dias ${ }^{4}$, \\ Vera Lúcia Dias Siqueira ${ }^{1}$ e Rosilene Fressatti Cardoso ${ }^{1}$
}

\begin{abstract}
RESUMO
A febre tifóide é doença bacteriana aguda causada por Salmonella enterica sorotipo typhi, que é adquirida pela ingestão de água ou alimento contaminado. 0 objetivo do presente trabalho é descrever um caso de febre tifóide ocorrido em Maringá, após três anos sem notificação da doença no Estado do Paraná.
\end{abstract}

Palavras-chaves: Salmonella enterica sorotipo typhi. Febre tifóide. Diagnóstico.

\begin{abstract}
Typhoid fever is an acute bacterial disease caused by Salmonella enterica serotype typhi, which is acquired by consumption of contaminated food or water. This paper had the aim of describing a case of typhoid fever that occurred in Maringá, State of Paraná, after three years without any notifications of the disease.
\end{abstract}

Key-words: Salmonella enterica serotype typhi. Typhoid fever. Diagnosis.

A febre tifóide (FT) é uma infecção sistêmica aguda, causada por Salmonella enterica sorotipo typhi. É comum em países em desenvolvimento e está associada a baixos níveis socioeconômicos e precárias condições de saneamento ${ }^{9}$. Os humanos são os únicos reservatórios ${ }^{12}$, podendo ser portadores assintomáticos, sendo 0 doente ou o portador de extrema importância na epidemiologia da doença. A transmissão ocorre via fecal-oral por veiculação hídrica ou alimentar'. Em áreas endêmicas a maioria dos casos ocorre em pessoas com idade de 3 a 19 anos $^{19}$.

A febre tifóide é ainda um grande problema de saúde pública afetando no mínimo 20 a 30 milhões de pessoas com uma significativa mortalidade em países em desenvolvimento ${ }^{18}$. A ocorrência é maior em países em desenvolvimento da Ásia, África, Caribe e América Central e do Sul ${ }^{3}$. Têm sido relatadas taxas de incidência de 198 casos/100.000 habitantes em Delta do Mekong, Vietnã e de 980 casos/100.000 habitantes em Deli, Índia ${ }^{7}$. É uma doença incomum em países industrializados como Estados Unidos, Japão, Canadá, Austrália e alguns países da Europa sendo os novos casos notificados de pessoas que viajaram para áreas endêmicas ${ }^{1317}$.
No Brasil, as regiões norte e nordeste são as que apresentam maior incidência, refletindo as precárias condições de saneamento básico nessas áreas do país ${ }^{10}$. Entre 2004 e 2006, foram notificados 1.539 casos de febre tifóide no Brasil ${ }^{11}$. No Paraná, entre 1980 e 2003, 1.030 casos foram notificados, sendo a incidência em 2003, de 0,01 casos/100.000 habitantes. Nos anos de 2004 e 2005, não houve notificação de casos da doença no estado ${ }^{10}$.

Segundo a última pesquisa nacional de saneamento básico, realizada pelo Instituto Brasileiro de Geografia e Estatística (IBGE) ${ }^{6}$ em 2000, dos 5.507 municípios brasileiros, pouco mais da metade (52,2\%) possuíam serviços de esgotamento sanitário. No Paraná, 96\% dos municípios têm rede geral de abastecimento de água e quase 23\% tem rede coletora de esgoto ${ }^{6}$. Ao contrário do que acontece em boa parte dos municípios do país, Maringá tem um índice de atendimento com coleta e tratamento de esgoto de $88,4 \% 5$.

A sintomatologia clássica da doença consiste em febre prolongada, cefaléia, mal-estar geral, anorexia, bradicardia relativa, esplenomegalia, manchas rosadas no tronco (roséolas tíficas), desconforto abdominal (constipação em adultos e diarréia em crianças) e tosse seca ${ }^{919}$.

1. Disciplina de Bacteriologia Clínica, Departamento de Análises Clínicas, Universidade Estadual de Maringá, Maringá, PR 2. Laboratório de Ensino e Pesquisa em Análises Clínicas, Universidade Estadual de Maringá, Maringá, PR 3. Laboratório Central do Estado do Paraná (LACEN), Curitiba, PR 4. Hospital Municipal de Maringá Dra. Thelma Villanova Kasprowicks, Maringá, PR.

Endereço para correspondência: Prof ${ }^{ \pm}$Rosilene Fressatti Cardoso. Deptº de Análises Clínicas/UEM. Av. Colombo, 5790 Bloco J-90 sala 5, 87020-900 Maringá, PR.

Tel: 5544 3261-4825; Fax: 5544 3261-4797

e-mail: rfcardoso@uem.br

Recebido para publicação em 13/12/2007

Aceito em 13/11/2008 
Após a ingestão, o bacilo tífico alcança o intestino grosso, rapidamente penetra na mucosa do epitélio via enterócitos e na lâmina própria é fagocitado por macrófagos. Alguns bacilos permanecem no tecido linfóide do intestino grosso e outros são drenados para os linfonodos mesentéricos. Acredita-se que os bacilos alcancem a corrente circulatória principalmente pela drenagem linfática mesentérica e por meio do ducto toráxico alcancem a circulação geral. Após esta bacteremia primária, 0 patógeno permanece intracelular em todos os órgãos do sistema monocítico macrofágico (baço, fígado, medula óssea, etc.) ${ }^{19}$, onde fica incubado de uma a três semanas ${ }^{15}$.

A falta de sinais e sintomas específicos da FT dificulta 0 diagnóstico clínico. A hemocultura e cultura de medula óssea são métodos laboratoriais sensíveis (80 e 95\%, respectivamente) para um diagnóstico definitivo dependente do isolamento de Salmonella typhi ${ }^{1419}$, porém sendo esta última tecnicamente mais complexa de ser realizada.

O isolamento de Salmonella typhi das fezes é sugestivo de FT, entretanto as condições clínicas devem ser avaliadas ${ }^{19}$. A sensibilidade da cultura de fezes depende da porção de fezes cultivada e a positividade aumenta com a duração da doença ${ }^{814}$.

O teste sorológico para FT (reação de Widal) apresenta valor diagnóstico limitado, uma vez que são observadas reações cruzadas com outras espécies de Salmonella e uma sensibilidade de $70 \%{ }^{8}$.

Métodos moleculares utilizando protocolos de reação em cadeia da polimerase (PCR) e sondas de DNA também têm sido desenvolvidos para detectar Salmonella typhi diretamente no sangue, mas não são amplamente realizados onde a FT é endêmica ${ }^{14}{ }^{16}$ sendo particularmente úteis em casos de hemoculturas negativas ${ }^{16}$.

0 esquema terapêutico preconizado pelo Ministério da Saúde ${ }^{9}$ para os casos de FT é o emprego de cloranfenicol ou ampicilina, sulfametoxazol-trimetoprima, amoxicilina ou ainda, em situações que impedem o emprego destes, recomenda-se o uso de ciprofloxacino, ofloxacino ou ceftriaxona. A resistência de cepas de Salmonella typhi para estes fármacos tem se tornado comum, particularmente em certas regiões da Ásia e América Latina ${ }^{8}$, onde os fármacos de escolha nesta situação são azitromicina ou cefalosporinas de terceira geraçã $0^{14}$.

0 objetivo do presente trabalho é descrever um caso de febre tifóide ocorrido em Maringá, após 3 anos sem notificação da doença no Estado do Paraná.

\section{RELATO DO CASO}

W.D.S, 13 anos de idade, sexo masculino, residente no perímetro urbano de Maringá, Paraná, procurou o pronto atendimento do Hospital Municipal de Maringá Dra. Thelma Villanova Kasprowicks, no mês de julho de 2007, queixandose de febre há 6 dias, dores generalizadas pelo corpo, astenia progressiva e cefaléia. Apresentava secreção nasal purulenta há uma semana, necessitando de observação hospitalar por sinusite. Ao exame inicial apresentou-se afebril, eupnéico, consciente, com astenia leve, com ausência de sinais meníngeos e sem foco infeccioso aparente. Foram prescritos dipirona $1 \mathrm{~g}$ endovenoso (EV) de 6/6 horas e cefalotina $1 \mathrm{~g}$ EV de 6/6h. Com base em critérios clínico-epidemiológicos as hipóteses diagnósticas iniciais foram dengue e sinusite. Foi realizado exame radiológico dos seios da face com resultado não compatível com sinusite.

A investigação laboratorial procedida no dia da consulta revelou no hemograma: hemácias: 5,95milhões $/ \mathrm{mm}^{3}$, hematócrito: 42,1\%, hemoglobina: 13,0g/dL, leucócitos: 3.500/ $\mathrm{mm}^{3} \mathrm{e}$ diferencial (bastonetes: 5\%, segmentados: 49\%, linfócitos: 41\%, linfócitos atípicos: 3\%, monócitos: $2 \%$ ), plaquetas: $130.000 / \mathrm{mm}^{3}$ e velocidade de hemossedimentação: $12 \mathrm{~mm}$. Como o menor não apresentou melhora, foi internado mantendo-se 0 antimicrobiano e antipirético já em uso e acrescentou-se paracetamol 750mg via oral de 6/6h. 0 mesmo continuou com picos febris de até $39,2^{\circ} \mathrm{C}$. Foi realizado novo hemograma que revelou piora no quadro: hemácias: 5,72milhões/mm3, hematócrito: 40,6\%, hemoglobina: 12,1g/dL, leucócitos: $3.300 / \mathrm{mm}^{3}$ e diferencial (metamielócitos: 4\%, bastonetes: $28 \%$, segmentados: $40 \%$, linfócitos: $21 \%$, monócitos: $7 \%$ ) e plaquetas: $120.000 / \mathrm{mm}^{3}$.

No segundo dia de internação, persistiu o quadro de febre $\left(39,8^{\circ} \mathrm{C}\right)$, sendo suspenso a cefalotina e o paracetamol. No terceiro dia de internação, observou-se prostração, com hiporexia, emese após a medicação e gengivorragia discreta. Foi prescrito ceftriaxona $2 \mathrm{~g}$ EV de $12 / 12 \mathrm{~h}$ e solicitados exames laboratoriais que demonstraram: hemácias: 5,96milhões $/ \mathrm{mm}^{3}$, hematócrito: 41,7\%, hemoglobina: 13,0g/dL, leucócitos: 3.700/ $\mathrm{mm}^{3}$ e diferencial (bastonetes: $20 \%$, segmentados: 30\%, linfócitos: 40\%, linfócitos atípicos: $2 \%$, monócitos: $8 \%$ ) e plaquetas: $146.000 / \mathrm{mm}^{3}$. Os exames bioquímicos realizados foram: sódio: 139mmol/L, potássio: $4,5 \mathrm{mmol} / \mathrm{L}$, creatinina: $1,35 \mathrm{mg} / \mathrm{dL}$, aspartato aminotransferase (AST): 398U/L, alanina aminotransferase (ALT): 150U/L e uréia: $24 \mathrm{mg} / \mathrm{dL}$. Em seguida, foi solicitada sorologia para dengue e hemocultura. A sorologia resultou não reagente e a hemocultura (2 amostras de sangue) revelou crescimento bacteriano, após 24 e 25 horas de incubação, nas duas amostras, sendo detectado pela coloração de Gram presença de bacilos Gram negativos. 0 resultado final da hemocultura liberado no $8^{\circ}$ dia de internação confirmou Salmonella typhi.

Houve piora do estado geral do $3^{\circ}$ dia de internação até o $6^{\circ}$ dia. No $7^{\circ}$ dia o paciente relatou tosse discreta, fato que não se repetiu. No exame físico observou-se fígado a $2 \mathrm{~cm}$ do rebordo costal direito no $6^{\circ}$ e $7^{\circ}$ dia de internação; constipação intestinal com episódios de evacuação normal no $3^{\circ}$ e $6^{\circ}$ dia de internação, regularizando sua função intestinal a partir do $10^{\circ}$ dia de internação e $8^{\circ}$ dia de tratamento com ceftriaxona. A diurese se apresentou em volume e freqüiência normal, notando-se no $2^{\circ}$ e $6^{\circ}$ dia de internação uma coloração escura. 0 paciente apresentou-se afebril a partir do $7^{\circ}$ dia de internação $\left(5^{\circ}\right.$ dia de tratamento com ceftriaxona; mantida até $013^{\circ}$ dia de internação). Evoluiu com melhora clínica e laboratorial apresentando no penúltimo dia de internação os seguintes resultados de exames: hemácias: 5,73 milhões $/ \mathrm{mm}^{3}$, hematócrito: $41,4 \%$, hemoglobina: 12,9g/dL, leucócitos: 4.600/ $\mathrm{mm}^{3}$ e diferencial (bastonetes: $0 \%$, segmentados: 23\%, linfócitos: $67 \%$, eosinófilos: 2\%, monócitos: 
8\%); os exames bioquímicos realizados foram: sódio: 145mmol/ L, potássio: 4,4mmol/L, creatinina: $0,86 \mathrm{mg} / \mathrm{dL}$, aspartato aminotransferase (AST): 75U/L, alanina aminotransferase (ALT): 103U/L e proteína C reativa: $0,35 \mathrm{mg} / \mathrm{dL}$.

Identificação bioquímica, sorológica e teste de sensibilidade aos antimicrobianos. A identificação dos isolados nas duas amostras de sangue e o teste de sensibilidade aos antimicrobianos foram realizados empregando-se o sistema automatizado AUTO-SCAN-4 (Dade Behring Inc., West Sacramento, CA, USA). Foram realizadas provas bioquímicas adicionais como fermentação da glicose, rhamnose, arabinose e dulcitol, motilidade, produção de $\mathrm{H}_{2} \mathrm{~S}$, descarboxilação da lisina e ornitina, produção de gás, utilização do citrato e produção de indol. A identificação sorológica de Salmonella typhi foi realizada por aglutinação em lâmina, utilizando o sorokit para Salmonella que emprega soros para antígenos somáticos $\left(\mathrm{A}, \mathrm{B}, \mathrm{C}_{1}, \mathrm{C}_{2}, \mathrm{D}\right.$ e E), flagelares e Vi (Probac do Brasil, São Paulo). A identificação bioquímica, pelo sistema automatizado, dos bacilos Gram negativos isolados nas duas amostras de sangue revelou Salmonella typhi. Provas bioquímicas complementares reforçaram a identificação pelo perfil bioquímico de fermentador da glicose sem produção de gás, motilidade positiva, produção fraca de $\mathrm{H}_{2} \mathrm{~S}$ e descarboxilação da lisina, porém não da ornitina.

Outras provas como utilização do citrato, produção de indol e fermentação da rhamnose, arabinose e dulcitol apresentaram resultados negativos compatíveis com a espécie identificada pelo sistema automatizado. Inicialmente realizou-se a reação de aglutinação com os soros polivalentes somáticos, flagelares e Vi, os quais apresentaram reações de aglutinação somente para os dois primeiros. Considerando a suspeita de Salmonella typhi foi realizada aglutinação em lâmina com os soros monovalentes somático D e flagelar d que apresentaram reação de aglutinação, finalizando desta forma a identificação de Salmonella typhi. 0 isolado apresentou sensibilidade a todos os antimicrobianos testados e padronizados pelo CLSI (Clinical Laboratory Standard

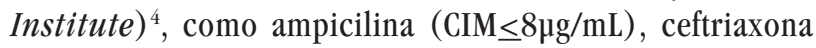
$(\mathrm{CIM} \leq 8 \mu \mathrm{g} / \mathrm{mL})$, ciprofloxacino $(\mathrm{CIM} \leq 1 \mu \mathrm{g} / \mathrm{mL})$ e sulfametoxazoltrimetoprima $(\mathrm{CIM} \leq 2 / 38 \mu \mathrm{g} / \mathrm{mL})$.

Medidas de controle adotadas. A conduta adotada frente a este caso de FT foi imediata, tanto na notificação do caso quanto na vigilância. Foi procedida busca ativa de casos no domicílio, identificação de comunicantes do paciente e pesquisa de portadores realizando coprocultura? .

\section{DISCUSSÃ0}

A febre tifóide é doença sistêmica, sendo os sítios mais comuns de infecção secundária o fígado, baço, medula óssea, vesícula biliar e placas de Peyer da porção terminal do íleo ${ }^{14}$. Este acometimento múltiplo dos órgãos pode explicar alterações que ocorrem nesta doença como hepatoesplenomegalia, icterícia, colúria, entre outras.

A investigação do presente caso foi conduzida por exames clínico, radiológico e laboratorial. A avaliação hematológica demonstrou diminuição de plaquetas e leucócitos com desvio a esquerda, o que nem sempre é observado $0^{3415}$, provavelmente por não se tratar de casos agudos.

A elevação dos valores de AST e ALT foi observada neste caso, atingindo níveis sete vezes o limite normal superior para AST e mais de duas vezes para ALT, no sétimo dia de internação. 0 aumento das enzimas hepáticas ocorre principalmente em complicações como hepatite colestática ${ }^{14} 15$.

0 fato de o paciente ter sido examinado no início da doença, e ter sido solicitado a hemocultura para esclarecer o quadro febril, foi fator determinante para o isolamento de Salmonella typhi no sangue que é inversamente proporcional ao tempo de evolução da doença ${ }^{15}$.

0 tratamento iniciado com ceftriaxona, mesmo sem um diagnóstico definitivo do quadro infeccioso, foi mantido após o recebimento do resultado da hemocultura e do teste de sensibilidade aos antimicrobianos considerando a melhora clínica do paciente, e à observância de sensibilidade da bactéria isolada à ampicilina, ceftriaxona, ciprofloxacino e sulfametoxazoltrimetoprima.

A identificação sorológica de Salmonella typhi pelo teste de aglutinação em lâmina mostrou inicialmente resultado negativo para a pesquisa do antígeno Vi. Fato este explicado considerando que a expressão do antígeno Vi nesta bactéria é variável ${ }^{12}$, explicando assim a reação negativa frente ao soro anti Vi. A identificação somente foi finalizada após a utilização do soro para pesquisa do antígeno somático $\mathrm{D}$ e soro para a pesquisa do antígeno flagelar d, uma vez que a presença destes antígenos (D e d) junto com a observação de características bioquímicas como pequena produção de $\mathrm{H}_{2} \mathrm{~S}$ em meio específico e certa inatividade metabólica a determinados substratos, confirma a identificação bioquímica e sorológica desta bactéria ${ }^{12}$.

O serviço de vigilância epidemiológica foi notificado pelo Setor de Bacteriologia Clínica do Laboratório de Ensino e Pesquisa/ Universidade Estadual de Maringá (LEPAC/UEM) para adoção de medidas coletivas de prevenção visando à detecção do indivíduo carreador do microrganismo e limitar a expansão da FT. Segundo as diretrizes do Ministério da Saúde ${ }^{9}$ para detecção de portadores crônicos de Salmonella typhi, após a cura clínica e sete dias de término do tratamento, todo paciente deve fazer coprocultura de 3 amostras de fezes. Quanto aos comunicantes, a pesquisa do estado de portador deve ser feita em 7 amostras de fezes coletadas em dias sequienciais. Tal conduta foi seguida para este paciente e seus comunicantes, e as coproculturas foram negativas para Salmonella typhi, excluindo a possibilidade de portadores crônicos no paciente e nos comunicantes investigados.

Apesar de serem realizados esforços para detectar a fonte da infecção, este propósito não foi atingido. Neste caso em particular, apesar de a FT estar associada a situações de saneamento básico precário, os autores acreditam que este não deve ter sido o fator preponderante para o paciente contrair a doença, visto que o município de Maringá apresenta bons índices de saneamento básico5.

0 paciente e seus comunicantes foram orientados sobre medidas de higiene, como a lavagem das mãos e manipulação de 
alimentos. Portanto, o rápido diagnóstico clínico-laboratorial e a ação conjunta com o setor de vigilância epidemiológica foram de extrema importância para garantir uma rápida intervenção de medidas, visando à saúde do doente e de seus familiares e evitar a disseminação da doença.

\section{REFERÊNCIAS}

1. Alecrim WD, Loureiro ACSP, Moraes RS, Monte RL, Lacerda MVG. Febre tifóide: recaída por resistência antimicrobiana. Relato de caso. Revista da Sociedade Brasileira Medicina Tropical 35: 661-663, 2002.

2. Cardoso HC, Cardoso HM, Kahwage Neto SG, Redig Junior MM, Luna RFC, Braga MAG. Hematoquezia Maciça em Paciente com Febre Tifóide: 0 que Fazer? - Relato de caso e revisão de literatura. Jornal Brasileiro de Medicina 91: 38-40, 2006.

3. Center for Disease Control and Prevention. CDC Health Information for International Travel 2008. Prevention of Specific Infectious Diseases. Chapter 4. Disponível em <http://wwwn.cdc.gov/travel/yellowBookCh4-typhoid.aspx>. Acesso em: 30/11/2007), 2007.

4. Clinical and Laboratory Standards Institute. Performance Standards for Antimicrobial Susceptibility Testing. Sixteenth Informational Supplement. CLSI document M100-S-17, p. 98-102, 2007.

5. Governo do Paraná. Sanepar leva mais obras para Maringá. Agência Estadual de Notícias, Maringá, PR, 2008. Disponível em <http://www.aenoticias.pr.gov. br/modules/news/article.php?storyid=42156>. Acesso em: 05/11/2008.

6. Instituto Brasileiro de Geografia e Estatística. Pesquisa Nacional de Saneamento Básico 2000. Ministério do Planejamento, Orçamento e Gestão, Rio de Janeiro, p. 40, 2002. Disponível em <http://www.ibge.gov.br/home/estatistica/populacao/ condicaodevida/pnsb/default.shtm> Acesso em: 31/10/2008.

7. Lin FY, Vo AH, Phan VB, Nguyen TT, Bryla D, Tran CT, Ha BK, Dang DT, Robbins JB. The epidemiology of typhoid fever in the Dong Thap Province, Mekong Delta region of Vietnam. The American Journal of Tropical Medicine and Hygiene 62: 644-648, 2000

8. Maskalyk J. Typhoid fever. Canadian Medical Association Journal 169: 132, 2003.

9. Ministério da Saúde. Doenças Infecciosas e Parasitárias. Guia de bolso. 6 a ed., Ministério da Saúde, Brasília, 2006.

10. Ministério da Saúde. Febre tifóide-Distribuição de casos confirmados, por unidade federada. Brasil, 1980-2005, 2006. Disponível em < http://portal.saude. gov.br/portal/arquivos/pdf/ftifoide-2006.pdf>. Acesso em: 06/12/2007.

11. Ministério da Saúde. Agência Nacional de Vigilância Sanitária. Doenças e agravos de interesse de saúde pública internacional, 2007. Disponível em <http://www. anvisa.gov.Br/paf/viajantes/febre_tifoide.htm>. Acesso em: 03/08/2007.

12. Murray PR, Baron EJ, Jorgensen JH, Pfaller MA, Yolken RH. Manual of Clinical Microbiology. $9^{\text {th }}$ edition. ASM-Press, Washington DC, p. 664, 682, 2007.

13. Papadimitropoulos V, Vergidis PI, Bliziotis I, Falagas ME. Vaccination against typhoid fever in travellers: a cost-effectiveness approach. Clinical Microbiology and Infection 10: 681-683, 2004.

14. Parry CM, Hien CC, Dougan GG, White NJ, Farran JJ. Typhoid fever. The New England Journal of Medicine 347: 1770-1780, 2002.

15. Ramos FLP. Complicações na febre tifóide: relato de um caso atípico e considerações sobre suas implicações no diagnóstico e no controle. Revista da Sociedade Brasileira de Medicina Tropical 37: 90-92, 2004.

16. Song JH, Cho H, Park MY, Na DS, Moon HB, Pai CH. Detection of Salmonella typhi in the Blood of Patients with Typhoid Fever by Polymerase Chain Reaction. Journal of Clinical Microbiology 31: 1439-1443, 1993.

17. Taylor DN, Pollard RA, Blake PA. Typhoid in the United States and the risk to the international traveler. The Journal of Infectious Disease 148: 599-602, 1983.

18. Wilde H. Enteric fever due to Salmonella typhi and paratyphi a neglected and emerging problem. Vaccine 25: 5246-5247, 2007.

19. World Health Organization. Background document: The diagnosis, treatment and prevention of typhoid fever. Communicable Disease Surveillance and Response Vaccines and Biologicals, Switzerland, 2003. 